\title{
ANALISIS GAYA HIDUP TERHADAP STATUS KESEHATAN LANSIA DI PUSKESMAS SIMPANG IV SIPIN TAHUN
}

\author{
Analysis Of Lifestyle On Health Status Elderly In Simpang IV Sipin Health Center 2016
}

\author{
Willia Novita Eka Rini ${ }^{1}$
}

${ }^{1}$ Program Studi Kesehatan Masyarakat Fakultas Kesehatan Masyarkat Universitas Jambi

\begin{abstract}
Abstrak
Populasi penduduk lanjut usia (lansia) mengalami peningkatan di seluruh dunia, termasuk di Indonesia. Peningkatan tersebut diikuti dengan perubahan gaya hidup yang dapat menimbulkan gangguan kesehatan. Penelitian ini bertujuan untuk menganalisa gaya hidup (pola makan, aktivitas fisik, istirahat dan riwayat merokok) terhadap status kesehatan lanjut usia (lansia) di wilayah kerja Puskesmas Simpang IV Sipin tahun 2016. Jenis penelitian menggunakan metode observasional analitik dengan desain cross sectional. Subjek penelitian ini adalah lansia yang terdaftar dan mendapatkan pelayanan kesehatan di Puskesmas Simpang IV Sipin Tahun 2016. Data diperoleh langsung dari responden dengan menggunakan alat bantu kuesioner. Penelitian dilakukan dari bulan April-November 2016. Data di analisa menggunakan analisa univariatuntuk mendapatkan gambaran distribusi frekuensi responden yang meliputi gaya hidup lansia yang terdiri dari pola makan, aktivitas fisik, kebiasaan istirahat dan riwayat merokok. Analisis data yang digunakan adalah $c h i-$ square. Berdasarkan hasil penelitian,status kesehatan lansia di Puskesmas Simpang IV Sipin 56,1\% tergolong baik. Ada pengaruh gaya hidup (pola makan, aktivitas fisik, kebiasaan istirahat dan riwayat merokok) terhadap status kesehatan lanjut usia (lansia) di Puskesmas Simpang IV Sipin dengan $p$ value $(0,002 ; 0,000 ; 0,001 ; 0,001)$. Dengan adanya penelitian ini diharapkan sejak muda seseorang terbiasa memiliki gaya hidup sehat, sehingga ketika memasuki masa lansia seseorang terhindar dari berbagai masalah kesehatan.
\end{abstract}

Kata kunci: gaya hidup, status kesehatan lansia.

\begin{abstract}
The population of the elderly (elderly) has increased throughout the world, including in Indonesia. This increase is followed by lifestyle changes that can cause health problems. This study aimed to analyze lifestyle (diet, physical activity, rest and smoking history) on the health status of the elderly (elderly) in the working area of Simpang IV Sipin Health Center in 2016. The type of research used was observational analytic method with cross sectional design. The subjects of this study were the elderly who were registered and received health services at the Simpang IV Sipin Health Center in 2016. Data was obtained directly from the respondents using a questionnaire tool. The study was conducted from April to November 2016. Data was analyzed using univariate analysis to obtain an overview of the frequency distribution of respondents which included the lifestyle of the elderly consisting of diet, physical activity, resting habits and smoking history. The data analysis used is chisquare. Based on the results of the study, the health status of the elderly at Simpang IV Sipin Health Center was $56.1 \%$ classified as good. There was influence of lifestyle (diet, physical activity, rest habits and smoking history) on the health status of the elderly (elderly) in Simpang IV Sipin Health Center with p value $(0.002 ; 0,000 ; 0.001 ; 0.001)$. With this research, it is expected that since young people are accustomed to having a healthy lifestyle, so that when entering the period of the elderly one is protected from various health problems.
\end{abstract}

Keywords: lifestyle, elderly health status.

Korespondensi: Willia

Email: willianovita95@gmail.com 


\section{PENDAHULUAN}

Pada tahun 2006 jumlah lansia 19 juta orang dengan peningkatan sekitar $8,9 \%$ dengan usia harapan hidup 66,2 tahun. Tahun 2010 penduduk lansia diperkirakan sebanyak 23,9 juta orang dengan peningkatan $9,7 \%$ dengan usia harapan hidup 67,4 tahun. Dan diperkirakan pada tahun 2020 jumlah penduduk lansia di Indonesia akan mencapai 28,8 juta orang dengan peningkatan sekitar $11,34 \%$ dan usia harapan hidup 71,1 tahun. Diperkirakan pada tahun 2020-2025 Indonesia akan berada di peringkat empat dunia di bawah Cina, India, dan Amerika Serikat. ${ }^{1}$

Gaya hidup sehat dapat dilakukan dengan mengonsumsi makanan yang bergizi seimbang, melakukan aktivitas fisik/olahraga secara benar dan teratur dan tidak merokok.Hal ini tidak semudah yang dibayangkan. Demikian halnya dengan gaya hidup yang salah dapat memengaruhi kesehatan antara lain kurang minum air putih, kurang gerak, mengonsumsi makanan yang berkalori tinggi, kebiasaan istirahat yang tidak teratur dan kebiasaan merokok. ${ }^{2,3,4}$

Menurut Syumanda (2009), melalui gaya hidup yang tidak baik dapat menimbulkan berbagai penyakit. Perubahan gaya hidup seperti konsumsi makanan cepat saji, pola makan yang tidak baik, kebiasaan merokok dan kurangnya aktivitas fisik, aktivitas fisik yang serba praktis merupakan salah satu pemicu untuk timbulnya penyakit berbahaya seperti Diabetes Mellitus, Tekanan Darah Tinggi (hipertensi), Penyakit Jantung dan Stroke (Bustan, 2007).

Dari hasil sebuah studi tentang kondisi sosial ekonomi dan kesehatan lansia yang dilaksanakan Komnas Lansia di 10 propinsi tahun 2006, diketahui bahwa penyakit yang terbanyak diderita lansia adalah penyakit sendi (52,3\%), hipertensi $(38,8 \%)$, anemia $(30,7 \%)$ dan katarak (23\%). Penyakit-penyakit tersebut merupakan penyebab utama disability ataupun kelemahan pada lansia.Oleh karena itu perlu dilakukan pemeriksaan kesehatan secara berkala untuk mengetahui penyakit/masalah sedini mungkin. Dengan demikian proses penyakit dapat dihambat atau dicegah sedini mungkin agar tetap dalam keadaan sehat, baik fisik maupun mental serta sosial. ${ }^{1}$

Menurut penelitian Fitri (2008) di Bali, pada umumnya lansia perempuan mengalami keluhan sakit akut dan sakit kronis yang lebih tinggi dibandingkan laki-laki, keluhan sakit kronis dan sakit akut lebih banyak dialami oleh lansia yang berstatus kawin dibandingkan dengan lansia yang berstatus tidak kawin, pendidikan tidak langsung memengaruhi status kesehatan, tetapi melalui jenis pekerjaan dan pendapatan yang diperoleh sehubungan dengan pekerjaan, orang yang bekerja mempunyai status kesehatan yang lebih buruk dibandingkan orang yang tidak bekerja, orang yang tinggal di kota memiliki persentase yang tinggi untuk menderita keluhan sakit akut tetapi memiliki persentase keluhan sakit kronis lebih rendah daripada orang yang tinggal di desa.

Berdasarkan latar belakang tersebut peneliti ingin mengetahui apakah ada pengaruh gaya hidup (pola makan, aktivitas fisik, istirahat dan riwayat merokok) terhadap status kesehatan lanjut usia (lansia) di Puskesmas Simpang IV Sipin tahun 2016.

\section{METODE}

Penelitian ini adalah penelitian observasional analitik. Penelitian ini dilaksanakan di Puskesmas Simpang IV Sipin Kota Jambi dilaksanakan dari bulan AprilNovember 2016. Subjek penelitian adalah lansia di Puskesmas Simpang IV Sipin yang berumur 60-69 tahun yang datang mendapatkan pelayanan kesehatan di Puskesmas Simpang IV Sipin. Data diperoleh langsung dari responden dengan menggunakan alat bantu kuesioner.

Analisis data yang digunakan adalah chisquare yaitu merupakan analisis untuk mengetahui hubungan antara variabel 
independen terhadap variabel dependen, dengan menggunakan $\alpha=0,05$ (derajat kepercayaan $95 \%)$.

\section{HASIL DAN PEMBAHASAN}

\section{Distribusi Frekuensi Responden}

Berdasarkan Pola Makan di Puskesmas Simpang IV Sipin Tahun 2016

Variabel pola makan lansia dikategorikan menjadi 2 yaitu pola makan baik dan pola makan tidak baik. Berdasarkan hasil penelitian didapatkan bahwa pola makan lansia mayoritas tergolong tidak baik yaitu sebanyak 68 orang $(59,6 \%)$ dan yang tergolong pola makan baik sebanyak 46 orang $(40,4 \%)$. Hal dapat dilihat pada tabel 1

Tabel 1. Distribusi Frekuensi Responden Berdasarkan Pola Makan di Puskesmas Simpang

IV Sipin Tahun 2016

\begin{tabular}{lll}
\hline Pola makan & Frekuensi & Persentaase (\%) \\
\hline Baik & 46 & 40,4 \\
\hline Tidak baik & 68 & 59,6 \\
\hline Jumlah & 114 & 00 \\
\hline
\end{tabular}

Distribusi Frekuensi Responden

Berdasarkan Aktivitas Fisik di Puskesmas Simpang IV Sipin Tahun 2016

Variabel aktivitas fisik lansia dikategorikan menjadi 2 yaitu aktivitas cukup dan aktivitas tidak cukup. Berdasarkan hasil penelitian didapatkan bahwa aktivitas fisik lansia mayoritas tergolong cukup yaitu sebanyak 75 orang $(65,8 \%)$ dan yang tergolong aktivitas fisik tidak cukup sebanyak 39 orang $(34,2 \%)$, dapat dilihat pada tabel 2

Tabel 2. Distribusi Frekuensi Responden Berdasarkan Aktivitas Fisik di Puskesmas Simpang IV Sipin Tahun 2016

\begin{tabular}{llll}
\hline No & Aktivitas Fisik & Frekuensi & Persentaase (\%) \\
\hline $\mathbf{1}$ & Cukup & 75 & 65,8 \\
$\mathbf{2}$ & Tidak cukup & 39 & 34,2 \\
& Jumlah & 114 & 100 \\
\hline
\end{tabular}

Distribusi

Frekuensi

Responden

Berdasarkan Kebiasaan Istirahat di Puskesmas Simpang IV Sipin Tahun 2016

Variabel kebiasaan istirahat lansia dikategorikan menjadi 2 yaitu kebiasaan istirahat cukup dan kebiasaan istirahat tidak cukup. Berdasarkan hasil penelitian didapatkan bahwa lansia yang memiliki kebiasaan istirahat tidak cukup sebanyak 48 orang $(42,1 \%)$ sedangkan lansia yang memiliki kebiasaan istirahat cukup sebanyak 66 orang $(57,9 \%)$. Hal ini dapat dilihat pada tabel 3

Tabel 3. Distribusi Frekuensi Responden Berdasarkan Kebiasaan Istirahat di Puskesmas Simpang IV Sipin Tahun 2016

\begin{tabular}{llll}
\hline No & Istirahat & Frekuensi & Persentaase (\%) \\
\hline $\mathbf{1}$ & Cukup & 66 & 57,9 \\
\hline $\mathbf{2}$ & Tidak cukup & 48 & 42,1 \\
& Jumlah & 114 & 100 \\
\hline
\end{tabular}

\section{Distribusi Frekuensi Responden \\ Berdasarkan Riwayat Merokok di Puskesmas Simpang IV Sipin Tahun 2016}

Variabel riwayat merokok lansia dikategorikan menjadi 2 yaitu lansia yang memiliki riwayat merokok dan lansia yang tidak memiliki riwayat merokok. Berdasarkan hasil penelitian didapatkan bahwa banyak lansia memiliki riwayat merokok yaitu sebanyak 50 orang $(43,9 \%)$ dan yang tidak memiliki riwayat merokok sebanyak 64 orang $(56,1 \%)$. Hal ini dapat dilihat pada tabel 4

Tabel 4.4. Distribusi Frekuensi Responden Berdasarkan Riwayat Merokok di Puskesmas Simpang IV Sipin Tahun 2016 


\begin{tabular}{llll}
\hline No & Riwayat merokok & Frekuensi & Persenta: \\
\hline $\mathbf{1}$ & Merokok & 50 & 43,9 \\
$\mathbf{2}$ & Tidak merokok & 64 & 56,1 \\
& Jumlah & 114 & 100 \\
\hline
\end{tabular}

\section{Distribusi Frekuensi Responden}

Berdasarkan Status Kesehatan di Puskesmas Simpang IV Sipin Tahun 2016

Berdasarkan hasil penelitian didapatkan bahwa sebagian besar lansia memiliki status kesehatan buruk yaitu sebanyak 50 orang $(43,9 \%)$ dan selebihnya memiliki status kesehatan baik yaitu 64 orang $(56,1 \%)$, dapat dilihat pada tabel 5

\section{Tabel 5. Distribusi Status Kesehatan Lanjut} Usia (Lansia) di Puskesmas Simpang IV Sipin Tahun 2016

\begin{tabular}{llll}
\hline No & Status kesehatan & Frekuensi & Persentaase (' \\
\hline $\mathbf{1}$ & Baik & 64 & 56,1 \\
$\mathbf{2}$ & Buruk & 50 & 43,9 \\
& Jumlah & 114 & 100 \\
\hline
\end{tabular}

Hubungan Pola Makan dengan Status Kesehatan Lanjut Usia (Lansia) di Puskesmas Simpang IV Sipin Tahun 2016

Hasil analisis bivariat antara pola makan dengan status kesehatan lansia diperoleh dari 46 orang lansia yang pola makannya baik 34 orang $(73,9 \%)$ status kesehatannya baik, 12 orang $(26,1 \%)$ status kesehatannya buruk, sedangkan dari 68 orang lansia yang memiliki pola makan tidak baik, 30 orang $(44,1 \%)$ status kesehatannya baik dan 38 orang $(55,9 \%)$ status kesehatannya buruk. Hasil uji statistik chisquare didapatkan nilai p value 0,000 (p \&lt; 0,005), terbukti Ho ditolak sehingga dapat disimpulkan terdapat hubungan yang signifikan antara pola makan lansia dengan status kesehatan lansia. Dari hasil analisis ini diperoleh juga nilai

OR (Odds Ratio) = 3,589 (PR >1) artinya lansia yang memiliki pola` makan tidak baik mempunyai risiko memiliki status kesehatan buruk 3,589 kali lebih tinggi dibandingkan dengan lansia yang pola makannya baik. ${ }^{7}$ Hal ini dapat dilihat pada tabel 6 .

Tabel 6. Hasil Analisis Bivariat antara Pola Makan dengan Status Kesehatan Lanjut Usia (Lansia) di Puskesmas Simpang IV Sipin Tahun 2016

\begin{tabular}{|c|c|c|c|c|c|c|c|c|}
\hline \multirow{3}{*}{$\begin{array}{l}\text { Pola } \\
\text { makan }\end{array}$} & \multicolumn{6}{|c|}{ Status kesehatan } & \multirow[t]{3}{*}{ OR } & \multirow{3}{*}{$\begin{array}{l}\text { Nilai } \\
p\end{array}$} \\
\hline & \multicolumn{2}{|c|}{ Baik } & \multicolumn{2}{|c|}{ Buruk } & \multicolumn{2}{|c|}{ Total } & & \\
\hline & $\mathrm{N}$ & $\%$ & $\mathrm{~N}$ & $\%$ & $\mathrm{~N}$ & $\%$ & & \\
\hline Baik & 34 & 73,9 & 12 & 26,1 & 46 & 100 & 3.589 & .002 \\
\hline $\begin{array}{l}\text { Tidak } \\
\text { baik }\end{array}$ & 30 & 44,1 & 38 & 55,9 & 68 & 100 & & \\
\hline Jumlah & \multicolumn{2}{|l|}{64} & \multicolumn{2}{|l|}{50} & \multicolumn{2}{|l|}{114} & & \\
\hline
\end{tabular}

Hubungan Aktivitas Fisik dengan Status Kesehatan Lanjut Usia (Lansia) di Puskesmas Simpang IV Sipin Tahun 2016

Hasil analisis bivariat antara aktivitas fisik dengan status kesehatan lansia diperoleh dari dari 75 orang lansia yang aktivitas fisiknya cukup 52 orang $(69,3 \%)$ status kesehatannya baik, 23 orang $(30,7 \%)$ status kesehatannya buruk. Dari 39 orang lansia yang aktivitas fisiknya tidak cukup, 12 orang $(30,8 \%)$ status kesehatannya baik dan 27 orang $(69,2 \%)$ status kesehatannya buruk. Hasil uji statistik chisquare didapatkan nilai $\mathrm{p}$ value $0,000(\mathrm{p}<0,05)$, terbukti Ho ditolak, artinya terdapat hubungan yang signifikan antara aktivitas fisik lansia dengan status kesehatan lansia. Dari analisis ini diperoleh juga nilai OR (Odds Ratio) $=5,087$ $(\mathrm{PR}>1)$ artinya lansia yang aktivitas fisiknya tidak cukup memiliki risiko status kesehatan buruk 5,087 kali lebih tinggi dibandingkan dengan lansia yang memiliki aktivitas fisik cukup. $^{7}$ Hal ini dapat dilihat pada tabel 5.7

Tabel 7.

Hasil Analisis Bivariat antara Aktivitas Fisik dengan Status Kesehatan Lanjut Usia (Lansia) di Puskesmas Simpang IV Sipin Tahun 2016 


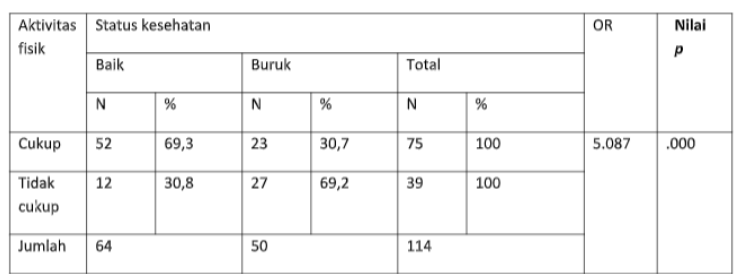

Hubungan Kebiasaan Istirahat dengan Status Kesehatan Lanjut Usia (Lansia) di Puskesmas Simpang IV Sipin Tahun 2016

Hasil analisis bivariat antara kebiasaan istirahat dengan status kesehatan lansia diperoleh dari 66 orang lansia yang kebiasaan istirahatnya cukup 46 orang $(69,7 \%)$ status kesehatannya baik, 20 orang $(30,3 \%)$ status kesehatannya buruk. Dari 48 orang lansia yang memiliki kebiasaan istirahat tidak cukup, 18 orang $(37,5 \%)$ status kesehatannya baik dan 30 orang $(62,5 \%)$ status kesehatannya buruk. Hasil uji statistik chi-square didapatkan nilai $\mathrm{p}$ value 0,001 ( $p<0,05)$, terbukti Ho ditolak, artinya terdapat hubungan yang signifikan antara kebiasaan istirahat lansia dengan status kesehatan lansia. Dari analisis ini diperoleh juga nilai OR (Odds Ratio) = 3,833 (PR > 1) artinya lansia yang memiliki kebiasaan istirahat tidak cukup memiliki risiko status kesehatan buruk 3,833 kali lebih tinggi dibandingkan dengan lansia yang memiliki kebiasaan istirahat cukup. ${ }^{7}$ Hal ini dapat dilihat pada tabel 8.

Tabel 8. Hasil Analisis Bivariat antara Kebiasaan Istirahat dengan Status Kesehatan

\section{Lanjut Usia (Lansia) di Puskesmas Simpang} IV Sipin Tahun 2016

\begin{tabular}{|c|c|c|c|c|c|c|c|c|}
\hline \multirow[t]{3}{*}{ Istirahat } & \multicolumn{6}{|c|}{ Status kesehatan } & \multirow[t]{3}{*}{ OR } & \multirow{3}{*}{$\begin{array}{l}\text { Nilai } \\
p\end{array}$} \\
\hline & \multicolumn{2}{|c|}{ Baik } & \multicolumn{2}{|c|}{ Buruk } & \multicolumn{2}{|c|}{ Total } & & \\
\hline & $\mathbf{N}$ & $\%$ & $\mathbf{N}$ & $\%$ & $\mathbf{N}$ & $\%$ & & \\
\hline Cukup & \begin{tabular}{|l|}
46 \\
\end{tabular} & 69,7 & 20 & 30,3 & 66 & \begin{tabular}{|l|}
100 \\
\end{tabular} & \multirow[t]{3}{*}{3.833} & \multirow[t]{3}{*}{.001} \\
\hline $\begin{array}{l}\text { Tidak } \\
\text { cukup }\end{array}$ & \begin{tabular}{|l|l|}
18 \\
\end{tabular} & 37,5 & 30 & 62,5 & 48 & \begin{tabular}{|l|}
100 \\
\end{tabular} & & \\
\hline Jumlah & 64 & & 50 & & 114 & & & \\
\hline
\end{tabular}

Hubungan Riwayat Merokok dengan Status

Kesehatan Lanjut Usia (Lansia) di Puskesmas Simpang IV Sipin Tahun 2016
Hasil analisis bivariat antara riwayat merokok dengan status kesehatan lansia diperoleh dari 50 orang lansia yang memiliki riwayat merokok, 19 orang (38\%) status kesehatannya baik, 31 orang (62\%) status kesehatannya buruk. Dari 64 orang lansia yang tidak memiliki riwayat merokok, 45 orang $(70,3 \%)$ status kesehatannya baik dan 19 orang $(29,7 \%)$ status kesehatannya buruk. Hasil uji statistik chi-square didapatkan nilai $p$ value 0,001 ( $p<0,005)$, terbukti Ho ditolak, artinya terdapat hubungan yang signifikan antara riwayat merokok lansia dengan status kesehatan lansia. Hal ini dapat dilihat pada tabel 9.

Tabel 9. Hasil Analisis Bivariat antara Riwayat Merokok dengan Status Kesehatan Lanjut Usia (Lansia) di Puskesmas Simpang IV Sipin Tahun 2016

\begin{tabular}{|c|c|c|c|c|c|c|c|c|}
\hline \multirow{3}{*}{$\begin{array}{l}\text { Riwayat } \\
\text { merokok }\end{array}$} & \multicolumn{6}{|c|}{ Status kesehatan } & \multirow[t]{3}{*}{ OR } & \multirow{3}{*}{$\begin{array}{l}\text { Nila } \\
\text { i } p\end{array}$} \\
\hline & \multicolumn{2}{|c|}{ Baik } & \multicolumn{2}{|c|}{ Buruk } & \multicolumn{2}{|c|}{ Total } & & \\
\hline & $\mathbf{N}$ & $\%$ & $\mathbf{N}$ & $\%$ & $\mathbf{N}$ & $\%$ & & \\
\hline Merokok & 19 & 38 & 31 & 62 & 50 & 100 & .259 & .001 \\
\hline $\begin{array}{l}\text { Tidak } \\
\text { merokok }\end{array}$ & 45 & 70,3 & 19 & 29,7 & 64 & 100 & & \\
\hline Jumlah & 64 & & 50 & & 11 & & & \\
\hline
\end{tabular}

\section{KESIMPULAN DAN SARAN}

Berdasarkan hasil penelitian dan pembahasan dapat diambil kesimpulan sebagai berikut:

1. Status kesehatan lansia di Puskesmas Simpang IV Sipin 56,1\% tergolong baik.

2. Ada pengaruh gaya hidup (pola makan, aktivitas fisik, kebiasaan istirahat dan riwayat merokok) terhadap status kesehatan lanjut usia (lansia) di Puskesmas Simpang IV Sipin dengan $p$ value $(0,002 ; 0,000 ; 0,001 ; 0,001)$

\section{Saran}

1. Dinas Kesehatan Kota Jambi diharapkan membuat kebijakan untuk peningkatan penyuluhan yang terkait dengan gaya hidup.

2. Puskesmas Simpang IV Sipin agar lebih meningkatkan penyuluhan yang terkait dengan pola makan yang baik, aktivitas fisik, istirahat 
yang cukup, menghentikan kebiasaan merokok dan perlu adanya dukungan keluarga.

\section{DAFTAR PUSTAKA:}

1. Nugroho, Wahyudi, 2008. Gerontik \& Geriatrik, Jakarta: EGC

2. Sediaoetama Achmad Djaeni, 2000, Ilmu Gizi, Jakarta Timur: Dian Rakyat

3. Santoso Soegeng, dkk, 2004, Kesehatan dan Gizi, Jakarta: PT. Asdi Mahasatya

4. Tamher, S \& Noorkasiani, 2009, Kesehatan Usia Lanjut dengan Pendekatan Asuhan Keperawatan, Jakarta, Penerbit Salemba Medika

5. Yasril dan Kasjono, H.S, 2009, Analisis Multivariat untuk Penelitian Kesehatan, Jogjakarta: Penerbit Mitra Cendikia Press

6. Bustan MN, 2007, Epidemiologi Penyakit Tidak Menular, Jakarta, Rineka

7. Sudigdo Sastroasmoro, 2008, Dasar-Dasar Metodologi Penelitian Klinis, Jakarta: Sagung Seto

8. Supariasa Nyoman I Dewa, dkk, 2002, Penilaian Status Gizi, Jakarta: EGC

9. Undang-Undang Kesehatan Republik Indonesia Nomor 36 Tahun 2009

10. Wirakusumah E, 2002, Tetap Segar di Usia Lanjut, Jakarta: Trubus Agriwidya 